OPEN ACCESS

Edited by:

Caterina Guzmán-Verri,

National University of Costa Rica,

Costa Rica

Reviewed by:

Mingsong Kang,

Canadian Food Inspection Agency,

Canada

Dazhi Jin,

Hangzhou Medical College, China

*Correspondence:

Uwe Groß

ugross@gwdg.de

Specialty section:

This article was submitted to Infectious Agents and Disease,

a section of the journal

Frontiers in Microbiology

Received: 16 December 2021

Accepted: 27 January 2022

Published: 16 February 2022

Citation:

Zimmermann O, Köchel H,

Bohne W, Pollok-Kopp B,

Passenberg P and Groß U (2022) $A$

Case Report and Review of the

Literature: Reactive Arthritis Caused

by Clostridioides difficile ribotype 027.

Front. Microbiol. 13:837422.

doi: 10.3389/fmicb.2022.837422

\section{A Case Report and Review of the Literature: Reactive Arthritis Caused by Clostridioides difficile ribotype 027}

\author{
Ortrud Zimmermann ${ }^{1}$, Heinrich Köchel ${ }^{1}$, Wolfgang Bohne ${ }^{1}$, Beatrix Pollok-Kopp ${ }^{2}$, \\ Peter Passenberg ${ }^{3}$ and Uwe Groß ${ }^{1 *}$
}

1 Institute for Medical Microbiology and Virology, University Medical Center Göttingen, Göttingen, Germany, ${ }^{2}$ Department of Transfusion Medicine, University Medical Center Göttingen, Göttingen, Germany, ${ }^{3}$ St. Martini Hospital, Clinic for Internal Medicine and Gastroenterology, Duderstadt, Germany

With an annual incidence of 250-300 per 100,000 inhabitants, reactive arthritis is not uncommon. However, the fact that Clostridioides difficile infection (CDI) can also lead to this complication is largely unknown. We report on a 69-years-old man who developed reactive arthritis of his right knee joint one week after antibiotic-associated diarrhea with evidence of $C$. difficile of the hypervirulent ribotype 027 . His female partner also became infected with $C$. difficile ribotype 027 , but did not develop reactive arthritis. The further investigation showed that the patient - in contrast to his partner - was HLA-B27 positive and had strong antibody levels against $C$. difficile. The case history together with the review of 45 other cases described so far shows that $C$. difficile can also lead to reactive arthritis. C. difficile-associated reactive arthritis (CDARA) is characterized by the fact that patients suffer from diarrhea or colitis after taking antibiotics, toxigenic $C$. difficile or only the toxins are detectable in the stool and there are no other explanations for the arthritis and diarrhea.

Keywords: Clostridioides difficile, Clostridium difficile, CDI, reactive arthritis, CDARA, IgA antibodies

\section{INTRODUCTION}

The frequency of Clostridioides difficile infections (CDIs) has been increasing worldwide for more than 15 years (Rupnik et al., 2009). It is assumed that there are at least 1,500 severe CDIs in Germany per year, with regional incidences varying between 0.2 (State of Saarland) and 6.6 diseases/100,000 inhabitants (State of Saxony-Anhalt). The most accepted typing scheme of C. difficile is based on PCR ribotyping. Like has been described for the general prevalence of $C$. difficile, large variation of 0.6 to $37.4 \%$ has also been found in Germany for the prevalence of ribotype 027 (Marujo and Arvand, 2020), with a 10.3\% prevalence rate of this C. difficile ribotype in the State of Lower Saxony (Seugendo et al., 2018). 418 (26\%) of the patients registered in Germany in 2020 did not survive their illness (Robert-Koch-Institute [RKI], 2020). In the United States, around 30,000 deaths per year have been reported (Lessa et al., 2015). Almost all clinically manifest CDIs develop colitis, the symptoms of which range from simple inflammation of the mucosa to a pseudomembranous form or even a megacolon (Lübbert et al., 2014). Extraintestinal forms such as, for example, reactive arthritis have hitherto been viewed as a very rare complication. Therefore, C. difficile is mostly overlooked as the cause of this potential secondary disease (Birnbaum et al., 2008; Mattila et al., 2013). Up to date - together with our patient - a total of 46 cases of $C$. difficile-associated reactive 
arthritis (CDARA) have been described. However, information on the respective ribotype that has caused this complication is only given for one other case, making the contribution of ribotype 027 for the development of CDARA unclear at the moment.

\section{CASE PRESENTATION}

A 69-years-old man from the State of Lower Saxony, Germany, presented at his doctors practice because of mushy stool and pain in the lower abdomen that had persisted for several days. At this time, no diagnosis of $C$. difficile infection was done. However, abdominal sonography showed clear signs of sigmoid diverticulitis with a considerable pericolic inflammatory reaction, whereupon the patient was treated intravenously with piperacillin/combactam ( $3 \mathrm{~g} \times 4.5 \mathrm{~g}$ daily) for five days. The diagnosis could be confirmed by computer tomography. His inflammation parameters decreased significantly during antibiotic therapy (drop in CRP from $100 \mathrm{mg} / \mathrm{l}$ to $20 \mathrm{mg} / \mathrm{l}$ ). The antibiotic therapy had to be administered orally for the upcoming discharge. Therefore, the patient was prescribed ciprofloxacin $250 \mathrm{mg}(1-0-1)$ for an additional seven days.

Under this therapy, the patient developed intestinal symptoms as early as the third day after discharge with watery, not bloody, but painful diarrhea, which occurred up to twenty times a day during the worst phase. Stool samples were cultivated on C. difficile selective agar (bioMérieux, Marcy-l'Étoile, France) for $48 \mathrm{hrs}$ under anaerobic conditions. Suspected colonies were sub-cultured on COS Columbia blood agar that was enriched with 5\% sheep blood (bioMérieux). C. difficile was identified with score values $\geq 2,000$ using MALDI-TOF mass spectrometry (Biotyper, Bruker Daltonics, Bremen, Germany). Bacterial toxins were determined using the Quik Chek Complete (Alere Techlab, Blacksburg, United States). PCR ribotyping was performed by Maja Rupnik, Slovenia, by capillary gel electrophoresis as described before (Seugendo et al., 2018). These examinations showed as cause of this diarrhea both the cultural proof of $C$. difficile ribotype 027 and the presence of toxins A and B. No other intestinal pathogens were detected. Since oral metronidazole therapy quickly improved the intestinal symptoms, the patient and his partner, who lived in the same household, decided to go on vacation to an island in the Northern Sea a week later. The drive there went without any further health problems; even immediately before the crossing to the island, no joint problems were yet evident.

Immediately after arrival at their holiday home, however, his right knee was so painfully swollen that he could hardly move it and would have liked to break off the vacation he had just started. In the course of the 14 days holidays, the symptoms of diarrhea improved after taking a bland diet and a preparation containing Saccharomyces boulardii (Perenterol $\left.{ }^{\circledR}\right)$. Therefore, he decided not to break off his vacation and not to see a doctor on the island, although the knee joint was still painfully swollen and restricted in movement. According to the patient's memory, he had already suffered reactive arthritis of the right knee joint after an enteric Salmonella infection more than 30 years ago. After his return from vacation, a previously planned total colonoscopy was performed, but the result was normal. Just five days after the colonoscopy, the patient developed another flare-up of severe intestinal infection with a high fever and severe diarrhea, so he sought medical advice.

Physical findings: We saw a $168 \mathrm{~cm}$ tall, $66 \mathrm{~kg}$ heavy patient in a reduced general condition. He stated that he had lost $9 \mathrm{~kg}$ in body weight and suffered from pain in the right knee joint within the last six weeks due to febrile diarrhea episodes. The function of the right knee was slightly terminally impaired in a side comparison. The cardiopulmonary auscultation findings and ECG were normal.

Diagnostic findings: Due to the pain in the right knee joint described in the anamnestic, a duplex sonography of the deep leg veins on the right was performed, which could rule out a thrombosis, but showed a slight knee joint effusion on the right. The microbiological examination of the stool again revealed C. difficile ribotype 027 , so that it was most likely a relapse of its original CDI. The X-ray findings of his right knee joint still showed a slight swelling of the capsule, but no relevant joint effusion. The function was ultimately slightly impaired in a comparison of the sides (Figure 1).

Intervention: With oral vancomycin therapy, his symptoms finally improved within a few days. The knee pain was treated conservatively with diclofenac resinate and local compresses with Kytta plasma for the night.

Follow-up and outcome: Further examinations did not reveal any evidence of persistent CDI in the patient. The 63-years-old female partner, who lives in the same household, was treated orally with ampicillin for a tooth abscess at the time of our patient's relapse. As a result, five days after the start of ampicillin therapy, she developed watery, non-bloody and hardly painful diarrhea, which was treated orally with metronidazole one day after the onset of symptoms. However, since the symptoms initially improved only slightly, she also provided a stool sample for microbiological analysis. The test for $C$. difficile toxin $\mathrm{A} / \mathrm{B}$ was positive; the cultural examination confirmed also a CDI with a RT027 strain. Since (i) C. difficile ribotype 027 is relatively rare in the State of Lower Saxony, (ii) both patients live as a pair in the very same household, and (iii) both were infected by an identical ribotype 027 at the very same time, it is very likely that they were infected by the same strain. However, since we did not perform whole genome sequencing at that time, final proof for strain identity could not be achieved. In contrast to her partner, this female patient suffered only from moderately severe diarrhea, which, however, dragged on for two months and was not accompanied by any joint involvement. Metronidazole was only taken intermittently for seven days due to poor tolerability. In addition, she did not consult a doctor because she did not suffer from fever or significant weight loss.

Analytics: Due to the diarrhea symptoms of the patient and his partner and the detection of toxigenic $C$. difficile strains in the examined stool, the bacterial isolates were ribotyped using PCR. Since the identical hypervirulent ribotype 027 of clade 2 was involved in both cases, it is very likely that the partner living in the same household had been infected by the patient. Interestingly, only the male patient developed reactive arthritis, and his intestinal symptoms were much more severe 


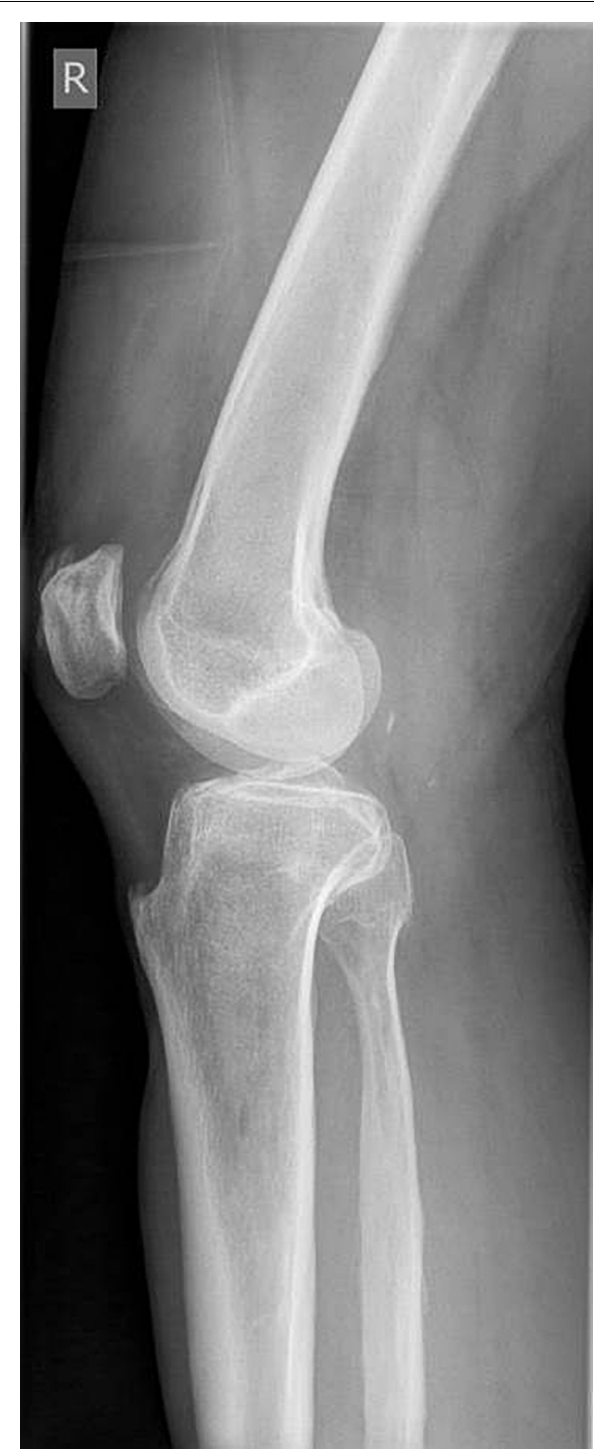

FIGURE $1 \mid X$ ray of the right knee.

than those of his female partner. For this reason, we assumed an immunopathological reaction as the cause of both the more severe intestinal symptoms and the development of reactive arthritis and examined the humoral immune response of the patient and his partner to $C$. difficile in an immunoblot (Pantosti et al., 1989). It was shown that the patient - in contrast to his partner - had a strong humoral immune response to the lowmolecular-weight S-layer protein SlpA from C. difficile, which is considered to be immunodominant (Figure 2).

\section{REVIEW OF THE LITERATURE AND DISCUSSION}

We performed a literature search on PubMed Central to identify articles published as of December 14, 2021. With the help

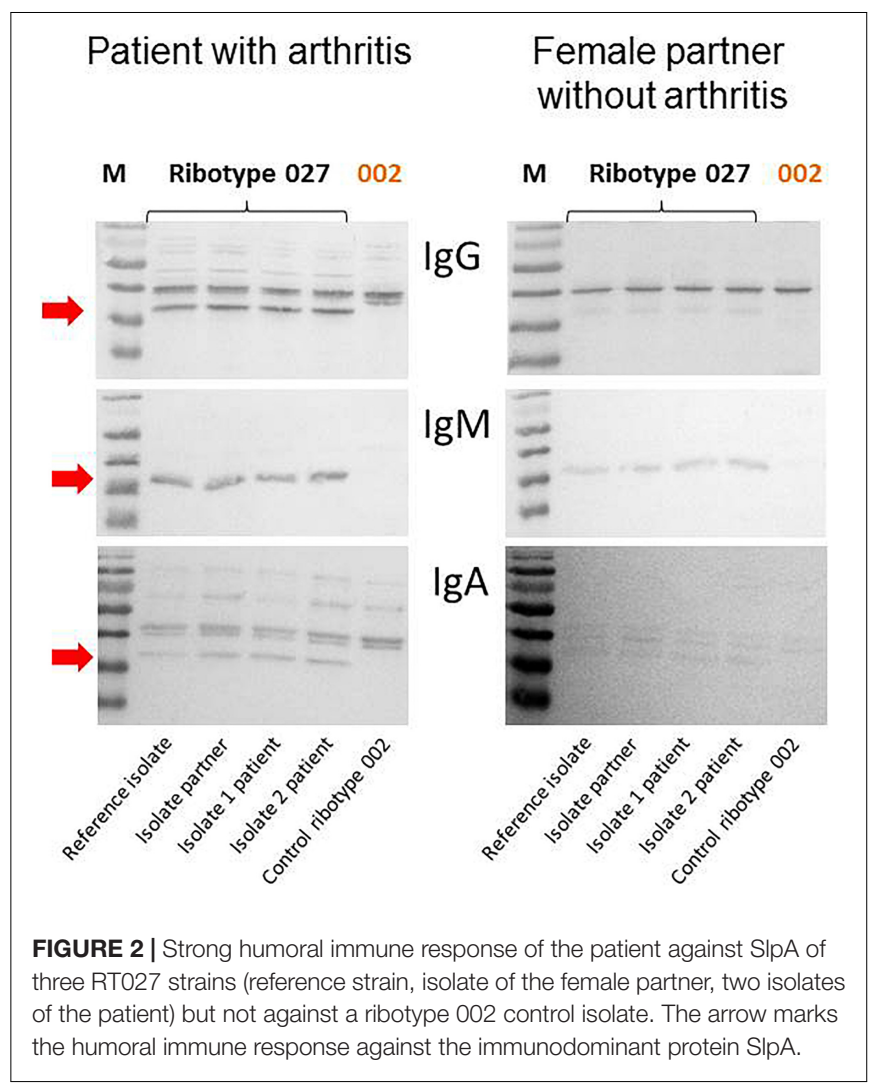

of the key words "Clostridium difficile, Clostridioides difficile" in combination with "reactive arthritis", 53 articles could be identified. Of these, 19 were removed because they were reviews, focused on basic science studies, the patients described had coinfections or no reactive arthritis, leaving 34 relevant articles for discussion (Table 1). In addition, articles were included that are important in understanding the possible pathogenesis of C. difficile-associated reactive arthritis (CDARA).

In the 46 patients described in Table 1, C. difficile was identified as a potential cause of reactive arthritis by culture $(n=21 ; 45.6 \%)$, toxin detection $(n=40 ; 87.0 \%)$ or a positive glutamate dehydrogenase $(\mathrm{GDH})$ test from stool specimens $(n=2 ; 4.3 \%)$. However, ribotyping of the bacterial isolates was only carried out in two of the 46 patients described so far. The mean age of the affected patients was 37.1 years with an increased occurrence in the age group 21-30 years. There was no clear association of reactive arthritis with the sex of the patients (25 male vs. 21 female). In contrast to our patient, $72.5 \%$ of those affected had oligo- or polyarthritis $(n=29 / 40)$. As in our patient, HLA-B27 was detected in $59.0 \%$ of the patients tested (23/39). Like our patient, $89.1 \%(41 / 46)$ of the patients described in Table 1 fulfilled all of the criteria established by Putterman and Rubinow (26) for the diagnosis of CDARA (Table 2). Only five of the affected patients reported no pre-existing antibiosis in their anamnesis.

The vast majority of patients $(n=31 / 41 ; 75.6 \%)$ took beta-lactam antibiotics in connection with reactive arthritis. Amoxicillin and ampicillin - possibly combined with a 
TABLE 1 | Published cases of $C$. difficile-associated reactive arthritis (CDARA) in chronological order.

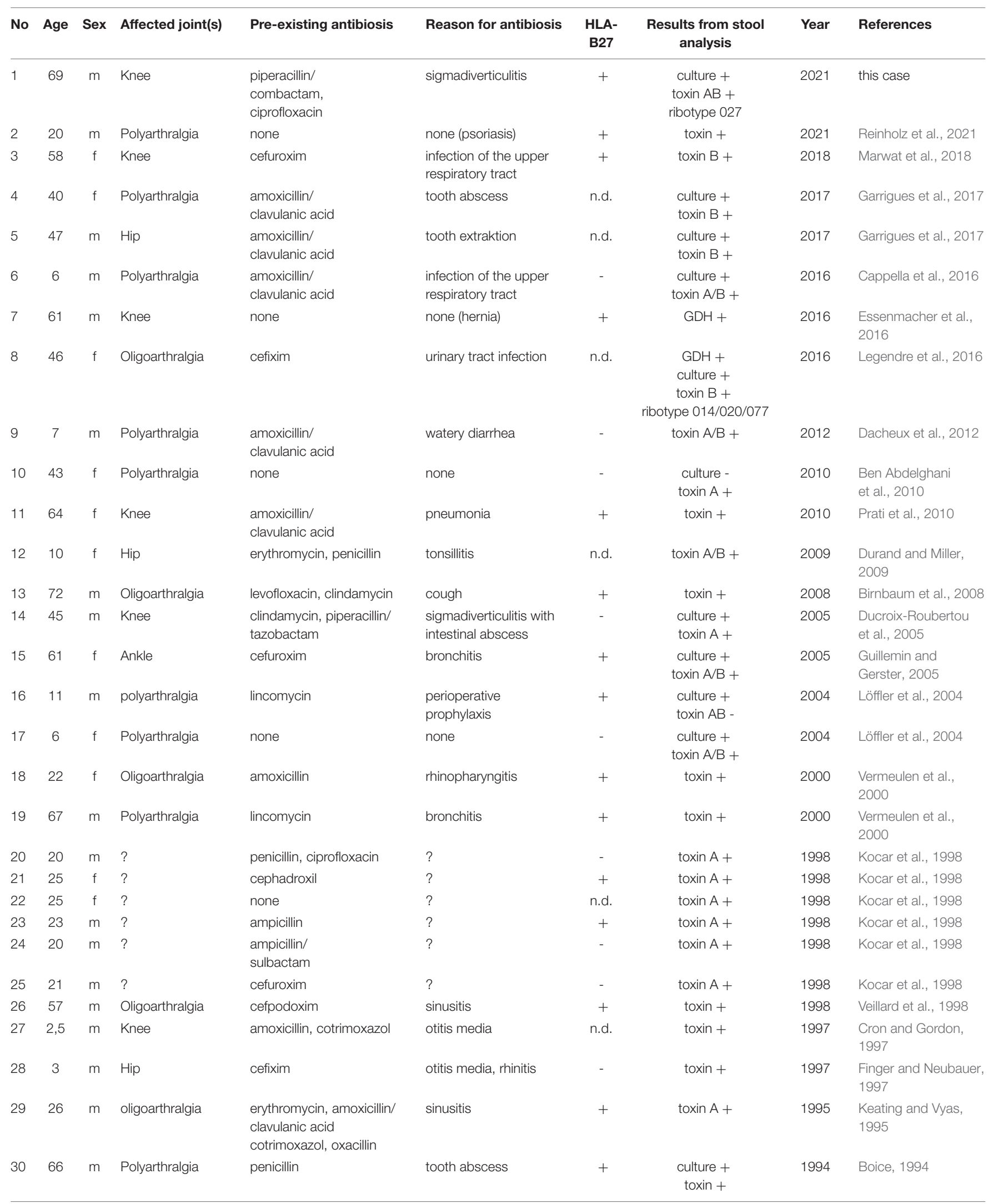


TABLE 1 | (Continued)

\begin{tabular}{|c|c|c|c|c|c|c|c|c|c|}
\hline No & Age & Sex & Affected joint(s) & Pre-existing antibiosis & Reason for antibiosis & $\begin{array}{l}\text { HLA- } \\
\text { B27 }\end{array}$ & $\begin{array}{c}\text { Results from stool } \\
\text { analysis }\end{array}$ & Year & References \\
\hline 31 & 61 & $f$ & Polyarthralgia & $\begin{array}{l}\text { ampicillin, gentamicin, } \\
\text { metronidazol }\end{array}$ & sigmadiverticulitis & - & toxin + & 1993 & $\begin{array}{l}\text { Putterman and } \\
\text { Rubinow, } 1999\end{array}$ \\
\hline 32 & 39 & $\mathrm{~m}$ & Oligoarthralgia & $\begin{array}{l}\text { ceftriaxon, cotrimoxazol, } \\
\text { bacitracin/ } \\
\text { neomycin }\end{array}$ & $\begin{array}{l}\text { postoperative } \\
\text { prophylaxis after hernia } \\
\text { surgery }\end{array}$ & n.d. & toxin $\mathrm{A} / \mathrm{B}+$ & 1993 & Sensini et al., 1993 \\
\hline 33 & 48 & $\mathrm{~m}$ & Polyarthralgia & oxacillin & infected insect bite & + & toxin + & 1992 & Cope et al., 1992 \\
\hline 34 & 56 & $f$ & Oligoarthralgia & cephalexin & urinary tract infection & + & $\begin{array}{c}\text { culture }+ \\
\text { toxin }+\end{array}$ & 1990 & Hayward et al., 1990 \\
\hline 35 & 23 & $f$ & Oligoarthralgia & clindamycin & $\begin{array}{l}\text { infection of the upper } \\
\text { respiratory tract }\end{array}$ & + & culture + & 1989 & $\begin{array}{l}\text { Hannonen et al., } \\
1989\end{array}$ \\
\hline 36 & 36 & $f$ & Oligoarthralgia & clindamycin & sialadenitis & - & culture + & 1989 & $\begin{array}{l}\text { Hannonen et al., } \\
1989\end{array}$ \\
\hline 37 & 45 & $\mathrm{~m}$ & Hand & penicillin, clindamycin & tonsillitis & + & culture + & 1989 & $\begin{array}{l}\text { Hannonen et al., } \\
1989\end{array}$ \\
\hline 38 & 29 & f & Polyarthralgia & clindamycin, cefoxitin & $\begin{array}{l}\text { bacteremia after } \\
\text { Cesarean section }\end{array}$ & + & toxin + & 1989 & $\begin{array}{l}\text { Mermel and Osborn, } \\
1989\end{array}$ \\
\hline 39 & 44 & $\mathrm{~m}$ & Oligoarthralgia & cloxacillin & cellulitis after insect bite & + & $\begin{array}{c}\text { culture }+ \\
\text { toxin }+\end{array}$ & 1988 & $\begin{array}{l}\text { Atkinson and } \\
\text { McLeod, } 1988\end{array}$ \\
\hline 40 & 22 & $\mathrm{~m}$ & Polyarthralgia & penicillin & tooth extraction & - & $\begin{array}{c}\text { culture }+ \\
\text { toxin }+\end{array}$ & 1988 & $\begin{array}{l}\text { Atkinson and } \\
\text { McLeod, } 1988\end{array}$ \\
\hline 41 & 28 & $f$ & Polyarthralgia & none & none & - & $\begin{array}{l}\text { culture - } \\
\text { toxin }+\end{array}$ & 1987 & $\begin{array}{l}\text { Paty and Nichols, } \\
1987\end{array}$ \\
\hline 42 & 61 & $\mathrm{~m}$ & Oligoarthralgia & cephalexin & $\begin{array}{l}\text { perioperative } \\
\text { prophylaxis }\end{array}$ & + & toxin + & 1984 & Lofgren et al., 1984 \\
\hline 43 & 27 & $f$ & Polyarthralgia & amoxicillin & $\begin{array}{l}\text { fever after surgery of } \\
\text { the uterus }\end{array}$ & - & $\begin{array}{c}\text { culture }+ \\
\text { toxin }+\end{array}$ & 1982 & $\begin{array}{l}\text { Abbott and Caughey, } \\
1982\end{array}$ \\
\hline 44 & 37 & $f$ & Polyarthralgia & clindamycin & combustion & + & $\begin{array}{c}\text { culture }+ \\
\text { toxin }+\end{array}$ & 1982 & $\begin{array}{l}\text { McCluskey et al., } \\
1982\end{array}$ \\
\hline 45 & 45 & $f$ & Oligoarthralgia & clindamycin & infection of the finger & - & $\begin{array}{c}\text { culture }+ \\
\text { toxin }+\end{array}$ & 1981 & Bolton et al., 1981 \\
\hline 46 & 53 & $f$ & Polyarthralgia & lincomycin, gentamicin & anorectal surgery & n.d. & $\begin{array}{c}\text { culture }+ \\
\text { toxin }+\end{array}$ & 1980 & $\begin{array}{l}\text { Fairweather et al., } \\
1980\end{array}$ \\
\hline
\end{tabular}

m, male, $f$, female, n.d., not done, ? = no information available.

beta-lactamase inhibitor - were clearly in the foreground with $29.3 \%(12 / 41)$ of the patients, followed by cephalosporins with $26.8 \%(11 / 41)$ of the patients. Eight of the patients with antibiotics (19.5\%) had taken clindamycin.

In contrast to his female partner, who was also infected with the $C$. difficile ribotype 027 and who did not develop reactive arthritis, HLA-B27 was detectable in our patient. He reported having had reactive arthritis after enteric Salmonella infection more than 30 years ago. Although determination of HLA-B27 was not done at that time, an association between this phenotypic marker and reactive arthritis is well known

TABLE 2 | Criteria for the diagnosis of $C$. difficile-associated reactive arthritis (mod. Putterman and Rubinow, 1999).

Presence of sterile inflammatory arthritis, together with or followed by: Diarrhea and/or colitis

Previous use of antibiotics

Proof of $C$. difficile or its toxin(s) in stool samples

Absence of alternative explanation/cause for arthritis and diarrhea making it likely that the patient's tendency to develop reactive arthritis after infection with defined intestinal pathogens (e.g., Salmonella enterica and C. difficile) is at least partially linked to HLA-B27 (Bentaleb et al., 2020). Even if this evidence attaches a role to HLA-B27 in the development of postinfectious reactive arthritis, only $59 \%$ of the described patients were positive for this biomarker (Table 1), making its precise involvement in pathogenesis still debatable (Bentaleb et al., 2020).

We therefore looked for other possible factors that predispose to the development of reactive arthritis after CDI or that may be suitable as prognostic biomarkers for the development of reactive arthritis after CDI in the future. Toxigenic CDI induces the production of interleukin-23, which - together with IL-17 - plays an important role in the development of inflammatory arthritis. In the context of this IL-23/IL-17 axis, B cells are activated for the production of autoantibodies (Lubberts, 2015). For this reason, we wanted to clarify whether the humoral immunity of the patient and his partner differ. In fact, a significantly stronger humoral immune response to the immunodominant $C$. difficile protein SlpA was detectable in the patient's serum compared to 
his female partner. These data are not intended as an explanation for pathogenesis of reactive arthritis but should rather give possible other explanations for the immunological difference between the patient and his female partner. This finding is also consistent with the persistence of $\operatorname{IgA}$ antibodies in reactive arthritis after infections with a whole range of other pathogens (Mäki-Ikola et al., 1994). It still remains to be clarified what role these antibodies play in the pathogenesis of CDARA and whether they are suitable as prognostic biomarkers for the development of reactive arthritis after CDI.

\section{CONCLUSION}

This case shows that CDI should in principle be considered as a rare cause of reactive arthritis. The identification or further development of corresponding biomarkers would be desirable, also to improve the state of knowledge on pathogenesis.

\section{DATA AVAILABILITY STATEMENT}

The original contributions presented in the study are included in the article/supplementary material, further inquiries can be directed to the corresponding author/s.

\section{REFERENCES}

Abbott, W. G., and Caughey, D. E. (1982). Reactive arthritis due to Clostridium difficile. NZ Med. J. 95:287.

Atkinson, M. H., and McLeod, B. D. (1988). Reactive arthritis associated with Clostridium difficile enteritis. J. Rheumatol. 15, 520-522.

Ben Abdelghani, K., Gerard-Dran, D., Morel, J., and Combe, B. (2010). Arthrite réactionnelle à Clostridium difficile. Rev. Med. Interne 31, e13-e15. doi: 10.1016/ j.revmed.2009.03.352

Bentaleb, I., Abdelghani, K. B., Rostom, S., Amine, B., Laatar, A., and Bahiri, R. (2020). Reactive arthritis: update. Curr. Clin. Microbiol. Rep. 7, 124-132. doi: 10.1007/s40588-020-00152-6

Birnbaum, J., Bartlett, J. G., and Gelber, A. C. (2008). Clostridium difficile: an under-recognized cause of reactive arthritis? Clin. Rheumatol. 27, 253-255.

Boice, J. L. (1994). Reactive arthritis induced by Clostridium difficile. West J. Med. $160,171-172$.

Bolton, R. P., Wood, G. M., and Losowsky, M. S. (1981). Acute arthritis associated with Clostridium difficile colitis. Br. Med. J. 283, 1023-1024. doi: 10.1136/bmj. 283.6298.1023

Cappella, M., Pugliese, F., Zucchini, A., and Marchetti, F. (2016). Clostridium difficile enterocolitis and reactive arthritis: a case report and review of the literature. Case Rep. Pediatr. 2016:1591753. doi: 10.1155/2016/159 1753

Cope, A., Anderson, J., and Wilkins, E. (1992). Clostridium difficile toxin-induced reactive arthritis in a patient with chronic Reiter's syndrome. Eur. J. Clin. Microbiol. Infect. Dis. 11, 40-43. doi: 10.1007/BF01971269

Cron, R. Q., and Gordon, P. V. (1997). Reactive arthritis to Clostridium difficile in a child. West J. Med. 166, 419-421.

Dacheux, C., Pruvost, I., Herbaux, B., and Nectoux, E. (2012). Polyarthrite réactionnelle à Clostridium difficile chez un enfant de 7 ans. Arch. Pediatr. 19, 607-611. doi: 10.1016/j.arcped.2012.03.011

Ducroix-Roubertou, S., Genet, C., Rogez, J. P., Weinbreck, P., and Denes, E. (2005). Arthrite réactionelle a Clostridium difficile. Med. Mal. Infect. 35, 419-421. doi: 10.1016/j.medmal.2005.04.003

\section{ETHICS STATEMENT}

Ethical review and approval was not required for the study on human participants in accordance with the local legislation and institutional requirements. The patients/participants provided their written informed consent to participate in this study.

\section{AUTHOR CONTRIBUTIONS}

UG, HK, and OZ had the initial idea to perform this study. $\mathrm{OZ}, \mathrm{WB}$, and $\mathrm{BP}-\mathrm{K}$ collected the samples and performed the laboratory analyses. PP did the clinical investigations. UG wrote the manuscript that was read and approved by all authors.

\section{FUNDING}

This work was funded by the State of Lower Saxony, Lower Saxony Vorab (VWZN2889/3215/3380).

\section{ACKNOWLEDGMENTS}

We thank Maja Rupnik for ribotyping and Daniela Wetzel for creating the immunoblot.

Durand, C. L., and Miller, P. F. (2009). Severe Clostridium difficile colitis and reactive arthritis in a ten-year-old child. Pediatr. Infect. Dis. J. 28, 750-751. doi: 10.1097/INF.0b013e31819bdaa3

Essenmacher, A. C., Khurram, N., and Bismack, G. T. (2016). A case of reactive arthritis due to Clostridium difficile colitis. J. Comm. Hosp. Int. Med. Perspect. 6:30151. doi: 10.3402/jchimp.v6.30151

Fairweather, S. D., George, R. H., Keighley, M. R. B., Youngs, D., and Burdon, D. W. (1980). Arthritis in pseudomembranous colitis associated with an antibody to Clostridium difficile toxin. J. R. Soc. Med. 73, 524-525.

Finger, D. R., and Neubauer, J. V. (1997). ). Reactive arthritis following Clostridium difficile colitis in a 3-year-old patient. J. Clin. Rheumatol. 3, 102-104. doi: 10.1097/00124743-199704000-00007

Garrigues, P., de Roux, T., Georgilopoulos, E., Wanono, E., and Mathieu, A. (2017). Arthrite réactionelle à Clostridium difficile: à propos de deux observations et revue de la littérature. Rev. Med. Interne. 38, 551-554. doi: 10.1016/j.revmed. 2016.12.015

Guillemin, P., and Gerster, J. C. (2005). Monoarthrite associée à une entérocolite à Clostridium difficile. Praxis 94, 471-474. doi: 10.1024/0369-8394.94.12.471

Hannonen, P., Hakola, M., Möttönen, T., and Oka, M. (1989). Reactive oligoarthritis associated with Clostridium difficile colitis. Scand. J. Rheumatol. 18, 57-60. doi: 10.3109/03009748909095404

Hayward, R. S., Wensel, R. H., and Kibsey, P. (1990). Relapsing Clostridium difficilie colitis and Reiter's syndrome. Am. J. Gastroenterol. 85, 752-756.

Keating, R. M., and Vyas, A. S. (1995). Reactive arthritis following Clostridium difficile colitis. West. J. Med. 162, 61-63.

Kocar, I. H., Caliskaner, Z., Pay, S., and Turan, M. (1998). Clostridium difficile infection in patients with reactive arthritis of undetermined etiology. Scand. J. Rheumatol. 27, 357-362. doi: 10.1080/03009749850154384

Legendre, P., Lalande, V., Eckert, C., Barbut, F., Fardet, L., Meynard, J. L., et al. (2016). Clostridium difficile associated reactive arthritis: case report and literature review. Anaerobe 38, 76-80. doi: 10.1016/j.anaerobe.2015.12.011

Lessa, F. C., Winston, L. G., McDonald, L. C., Emerging Infections Program C Difficile Surveillance Team (2015). Burden of Clostridium difficile infection in the United States. N. Engl. J. Med. 372, 2369-2370. doi: 10.1056/NEJMc1505190 
Löffler, H. A., Pron, B., Mouy, R., Wulffraat, N. M., and Prieur, A. M. (2004). Clostridium difficile-associated reactive arthritis in two children. Joint Bone Spine 71, 60-62. doi: 10.1016/S1297-319X(03)00056-3

Lofgren, R. P., Tadlock, L. M., and Soltis, R. D. (1984). Acute oligoarthritis associated with Clostridium difficile pseudomembranous colitis. Arch. Intern. Med. 144, 617-619.

Lübbert, C., Endres, J., and von Müller, L. (2014). Clostridium difficile infection guideline-based diagnosis and treatment. Dtsch. Ärztebl. Int. 111, 723-731. doi: 10.3238/arztebl.2014.0723

Lubberts, E. (2015). The IL-23-IL-17 axis in inflammatory arthritis. Nat. Rev. Rheumatol. 11:562. doi: 10.1038/nrrheum.2015.128

Mäki-Ikola, O., Lahesmaa, R., Heesemann, J., Merilahti-Palo, R., Saario, R., Toivanen, A., et al. (1994). Yersinia-specific antibodies in serum and synovial fluid in patients with Yersinia triggered reactive arthritis. Ann. Rheum. Dis. 53, 535-539. doi: 10.1136/ard.53.8.535

Marujo, V., and Arvand, M. (2020). The largely unnoticed spread of Clostridioides difficile PCR ribotype 027 in Germany after 2010. Infect. Pre. Pract. 2:100102. doi: 10.1016/j.infpip.2020.100102

Marwat, A., Mehmood, H., Hussain, A., Khan, M., Ullah, A., and Joshi, M. (2018). Clostridium difficile colitis leading to reactive arthritis: a rare complication associated with a common disease. J. Investig. Med. High Impact Case Rep. 6:2324709618767689. doi: 10.1177/2324709618767689

Mattila, E., Arkkila, P., Mattila, P. S., Tarkka, E., Tissari, P., and Antitila, V.J. (2013). Extraintestinal Clostridium difficile infections. Clin. Infect. Dis. 57, e148-e153. doi: 10.1093/cid/cit392

McCluskey, J., Riley, T. V., Owen, E. T., and Langlands, D. R. (1982). Reactive arthritis associated with Clostridium difficile. Aust. NZ. J. Med. 12, 535-537.

Mermel, L. A., and Osborn, T. H. (1989). Clostridium difficile associated reactive arthritis in an HLA-B27 positive female: report and literature review. J. Rheumatol. 16, 133-135.

Pantosti, A., Cerquetti, M., Viti, F., Ortisi, G., and Mastrantonio, P. (1989). Immunoblot analysis of serum immunoglobulin $\mathrm{G}$ response to surface proteins of Clostridium difficile in patients with antibiotic-associated diarrhea. J. Clin. Microbiol. 27, 2594-2597. doi: 10.1128/jcm.27.11.2594-2597.1989

Paty, J. G., and Nichols, R. E. (1987). Arthritis and non-antibiotic-associated pseudomembranous colitis. Arthritis Rheum. 30, 1075-1076. doi: 10.1002/art. 1780300920

Prati, C., Bertolini, E., Toussirot, E., and Wendling, D. (2010). Reactive arthritis due to Clostridium difficile. Joint Bone Spine 77, 190-192. doi: 10.1016/j.jbspin. 2010.01.007

Putterman, C., and Rubinow, A. (1999). Reactive arthritis associated with Clostridium difficile pseudomembranous colitis. Semin. Arthritis Rheum. 22, 420-426. doi: 10.1016/s0049-0172(05)80033-2
Reinholz, A., Mannuru, D., Bande, D., and Matta, A. (2021). Reactive arthritis: an unusual presentation of acute Clostridioides difficile colitis. BMJ Case Rep. 14:e240890. doi: 10.1136/bcr-2020-240890

Robert-Koch-Institute [RKI] (2020). Infektionsepidemiologisches Jahrbuch Meldepflichtiger Krankheiten für2020. Available online at: https://www. rki.de/DE/Content/Infekt/Jahrbuch/Jahrbuch_2020.html;jsessionid=AAC1084 22FC0C9CB7925F38DD0D9A728.internet062? $\mathrm{nn}=2374622$ (accessed on Dec $15,2021)$

Rupnik, M., Wilcox, M. H., and Gerding, D. N. (2009). Clostridium difficile infection: new developments in epidemiology and pathogenesis. Nat. Rev. Microbiol. 7, 526-536. doi: 10.1038/nrmicro2164

Sensini, A., Marroni, M., Bassotti, G., Farinelli, S., d'Alò, F., Gentili, A. M., et al. (1993). Clostridium difficile-associated reactive arthritis in an HLA-B27 negative male. J. Clin. Gastroenterol. 16, 354-358. doi: 10.1097/00004836-19930600000020

Seugendo, M., Janssen, I., Lang, V., Hasibuan, I., Bohne, W., Cooper, P., et al. (2018). Prevalence and strain characterization of Clostridioides (Clostridium) difficile in representative regions of Germany, Ghana, Tanzania, and Indonesia a comparative multi-center cross-sectional study. Front. Microbiol. 9:1843. doi: 10.3389/fmicb.2018.01843

Veillard, E., Guggenbuhl, P., Bello, S., Lamer, F., and Chalès, G. (1998). Reactive oligoarthritis in a patient with Clostridium difficile pseudomembranous colitis. Rev. Rhum. Engl. Ed. 65, 795-798.

Vermeulen, C., Lemaire, V., and Lioté, F. (2000). Manifestations articulaires liées à Clostridium difficile. Presse Med. 29, 476-481.

Conflict of Interest: The authors declare that the research was conducted in the absence of any commercial or financial relationships that could be construed as a potential conflict of interest.

Publisher's Note: All claims expressed in this article are solely those of the authors and do not necessarily represent those of their affiliated organizations, or those of the publisher, the editors and the reviewers. Any product that may be evaluated in this article, or claim that may be made by its manufacturer, is not guaranteed or endorsed by the publisher.

Copyright (c) 2022 Zimmermann, Köchel, Bohne, Pollok-Kopp, Passenberg and Groß. This is an open-access article distributed under the terms of the Creative Commons Attribution License (CC BY). The use, distribution or reproduction in other forums is permitted, provided the original author(s) and the copyright owner(s) are credited and that the original publication in this journal is cited, in accordance with accepted academic practice. No use, distribution or reproduction is permitted which does not comply with these terms. 